\title{
Mesenchymal stem cell-derived extracellular vesicles promote the in vitro proliferation and migration of breast cancer cells through the activation of the ERK pathway
}

\author{
XIAOHE ZHOU ${ }^{1 *}$, TAO $^{1,2^{*}}{ }^{*}$, YUFEI CHEN ${ }^{1}$, NANNAN ZHANG ${ }^{1}$, PENGLI WANG ${ }^{1}$, YINGYING LIANG ${ }^{2}$, \\ MELISSA LONG ${ }^{2}$, HAORAN LIU $^{1}$, JIAN MAO ${ }^{1}$, QIUYAN LIU ${ }^{3}$, XIAOCHUN SUN ${ }^{1}$ and HUABIAO CHEN ${ }^{1,2}$ \\ ${ }^{1}$ Jiangsu Key Laboratory of Clinical Laboratory Medicine, School of Medicine, Jiangsu University, Zhenjiang, \\ Jiangsu 212013, P.R. China; ${ }^{2}$ Vaccine and Immunotherapy Center, Massachusetts General Hospital and \\ Harvard Medical School, Boston, MA 02114, USA; ${ }^{3}$ National Key Laboratory of Medical Immunology, \\ Second Military Medical University, Shanghai 200433, P.R. China
}

Received August 10, 2018; Accepted February 14, 2019

DOI: $10.3892 /$ ijo.2019.4747

\begin{abstract}
Mesenchymal stem cells (MSCs) have been demonstrated to be involved in tumor progression and the modulation of the tumor microenvironment, partly through their secretome. Extracellular vesicles (EVs) are membranous nanovesicles secreted by multiple types of cells and have been demonstrated to mediate intercellular communication in both physiological and pathological conditions. However, numerous questions still remain regarding the underlying mechanisms and functional consequences of these interactions. The purpose of this study was to investigate the effects of human umbilical cord mesenchymal stem cell-derived EVs (hUC-MSC-EVs) on the proliferation, migration and invasion of human breast cancer cells. We successfully generated and identified hUC-MSCs and hUC-MSC-EVs which were used in this study. The results revealed that treatment of the MDA-MB-231 and MCF-7 human breast cancer cells with medium containing hUC-MSC-EVs significantly enhanced the proliferation, migration and invasion of the cells in vitro. Treatment of the cells with medium containing hUC-MSC-EVs also reduced E-cadherin expression and increased $\mathrm{N}$-cadherin expression,
\end{abstract}

Correspondence to: Professor Huabiao Chen, Vaccine and Immunotherapy Center, Massachusetts General Hospital and Harvard Medical School, 55 Fruit Street, Boston, MA 02114, USA E-mail: huabiao.chen@mgh.harvard.edu

Professor Xiaochun Sun, Jiangsu Key Laboratory of Clinical Laboratory Medicine, School of Medicine, Jiangsu University, 301 Xuefu Road, Zhenjiang, Jiangsu 212013, P.R. China

E-mail: xiaochun@ujs.edu.cn

*Contributed equally

Key words: breast cancer, epithelial-mesenchymal transition, mesenchymal stem cells, extracellular signal-regulated kinase pathway, extracellular vesicles thus promoting the epithelial-mesenchymal transition (EMT) of the breast cancer cells. Treatment of the breast cancer cells with extracellular signal-regulated kinase (ERK) inhibitor prior to the interaction with hUC-MSC-EVs significantly reversed the enhanced proliferation, migration and invasion, as well as the EMT of the breast cancer cells induced by the hUC-MSC-EVs. On the whole, these data indicate that hUC-MSC-EVs promote the invasive and migratory potential of breast cancer cells through the induction of EMT via the ERK pathway, leading to malignant tumor progression and metastasis. Taken together, the findings of this study suggest that targeting pathways to reverse EMT may lead to the development of novel therapeutic approaches with which to combat breast cancer.

\section{Introduction}

Breast cancer is the most frequent form of cancer among women (1-3) and the second main cause of cancer-related mortality among women (4,5). Triple-negative breast cancer (TNBC) is a common type of breast malignancy with higher rates of metastasis, heterogeneity, drug resistance and a poorer prognosis. TNBC is characterized by tumors with lack of estrogen receptor, progesterone receptor and human epidermal growth factor receptor 2 (6). The incidence rate of TNBC is increasing continuously, particularly in young women. At present, a range of therapeutic strategies are available for the treatment of breast cancer, including surgery, chemotherapy, radiotherapy, endocrine therapy and targeted therapy; however, there remains a large proportion of therapeutic failures (7). Thus, a better understanding of the mechanisms underlying the pathogenesis of tumor development, progression and metastasis may lead to the identification of novel prognostic biomarkers and to the development of novel therapeutic strategies for breast cancer.

Mesenchymal stem cells (MSCs) are multipotent stem cells that can be derived from various tissues, including the umbilical cord, bone marrow and adipose tissue (8-11). MSCs have the potential to differentiate into various cell types of 
the mesodermal germ layer, including osteoblasts, adipocytes and chondrocytes $(12,13)$. In addition, MSCs are known to migrate to sites of inflammation and injury, as well as to the hypoxic tumor microenvironment (14). A growing body of evidence has indicated that MSCs play crucial and complex roles in tumor development and progression by increasing the stemness of tumor cells, mediating tumor cell growth, promoting angiogenesis, suppressing immune responses and inducing drug resistance $(15,16)$. Several studies have demonstrated that MSCs can also contribute to the formation of the tumor microenvironment (17-20). The biological mechanisms underlying the recruitment of MSCs into the tumor microenvironment remain to be elucidated. In our previous study, it was found that the conditioned medium of hUC-MSCs promoted the proliferation and migration of breast cancer cells (21). Therefore, we hypothesized that the effects of hUC-MSCs take place primarily through secreted factors, and tumor development and progression are associated with hUC-MSC paracrine activities.

A large body of MSC research has focused on extracellular vesicles (EVs) derived from MSCs (MSC-EVs) and has demonstrated that MSC-EVs carry the properties of MSCs, such as the suppression of inflammatory responses, the repair of tissue damage, and the promotion of angiogenesis (22-24). EVs are membranous nanovesicles (30-1,000 $\mathrm{nm}$ in diameter) that are released by multiple cell types into the extracellular space in body fluids such as blood, urine and plasma, as well as into cell culture suspension (25). Based on their cellular origin, biological function and biogenesis, EVs can be categorized into exosomes (40-120 nm), microvesicles (50-1,000 nm) and apoptotic bodies (500-2,000 $\mathrm{nm}$ ) (26). EVs act as naturally secreted membrane vesicles containing proteins, lipids, and genetic material such as mRNAs and miRNAs (27-29). Therefore, we hypothesized that MSC-EVs can transport MSC-associated molecules to alter the physiology of target cells in an MSC-specific manner. MSC-EVs have been demonstrated as a novel mechanism of cell-to-cell communication in the development and progression of tumors (30). In order to better understand the mechanisms through which MSC-EVs affect breast cancer, in this study, we investigated the interaction between hUC-MSC-EVs and MDA-MB-231 and MCF-7 human breast cancer cell lines cells in vitro.

\section{Materials and methods}

Ethics statement. The experiments using human samples were approved by the Research Ethics Committee of Jiangsu University. All procedures performed in this study were in accordance with the Declaration of Helsinki.

Cell lines and cell culture. The MCF-7 and MDA-MB-231 human breast cancer cell lines cells were a gift from Dr W. Zhu (Department of Medicine, Jiangsu University, Zhenjiang, China), and were cultured in high-glucose Dulbecco's modified Eagle's medium (H-DMEM) (cat. no. 12100046; Gibco/Thermo Fisher Scientific, Waltham, MA, USA) with 10\% fetal bovine serum (FBS) (cat. no. FND500; ExCell Bio, Shanghai, China), $100 \mathrm{U} / \mathrm{ml}$ penicillin and $100 \mu \mathrm{g} / \mathrm{ml}$ streptomycin (cat. no. ST488; Beyotime, Jiangsu, China) under mycoplasma-free conditions at $37^{\circ} \mathrm{C}$ in $5 \% \mathrm{CO}_{2}$.
Isolation and characterization of hUC-MSCs. This study was performed using umbilical cord samples from 6 pregnant mothers who delivered full-term neonates, based on a pregnancy period of 37-41 weeks at the Affiliated Hospital of Jiangsu University during the period from May, 2015 to April, 2017. Fresh umbilical cords were collected from healthy donors after obtaining informed consent at the Affiliated Hospital of Jiangsu University. hUC-MSCs were isolated and cultured as described in our previous studies $(8,21,31)$. In brief, umbilical cord blood vessels were carefully removed to retain Wharton's jelly, and the remaining tissue was then cut into $1-\mathrm{mm}^{3}$ sized sections with scissors and placed in low glucose Dulbecco's modified Eagle's medium (L-DMEM) (cat. no. 31600034; Gibco/Thermo Fisher Scientific) with $10 \%$ FBS and antibiotics (100 U/ml penicillin and $100 \mu \mathrm{g} / \mathrm{ml}$ streptomycin). The cells were incubated at $37^{\circ} \mathrm{C}$ with $5 \% \mathrm{CO}_{2}$ in a humidified atmosphere and the medium was changed every 3 days thereafter. When the adherent cells reached nearly $80-90 \%$ confluence, the cells were digested with $0.25 \%$ trypsin-EDTA (Beijing Solarbio Science and Technology Co., Ltd., Beijing, China) and subcultured in new flasks for expansion. Cultured hUC-MSCs of passage 3 were used for further analyses.

Assessment of osteogenic and adipogenic potential. To assess the differentiation potential, hUC-MSCs were plated into 6-well plates and cultured with osteogenic induction medium, composed of L-DMEM supplemented with $0.1 \mu \mathrm{M}$ dexamethasone, $10 \mathrm{mM} \beta$-glycerophosphate, $4 \mu \mathrm{g} / \mathrm{ml}$ basic fibroblast growth factor (bFGF) and $50 \mu \mathrm{g} / \mathrm{ml}$ ascorbic acid (Sigma-Aldrich, St. Louis, MO, USA) for 14 days. The induction medium was changed every 3 days. Following 14 days of osteoblast differentiation, the cells were washed twice with PBS and fixed with $4 \%$ ice-cold paraformaldehyde for $30 \mathrm{~min}$. The cells were then stained using the Alkaline Phosphatase Color Development kit (cat. no. P0321; Beyotime) and imaged using a microscope (Ti-S; Nikon, Tokyo, Japan). Orange and red bodies were identified as calcium nodules. For adipogenic differentiation, the cells were plated into 24 -well plates in DMEM with $10 \% \mathrm{FBS}$ and $100 \mathrm{U} / \mathrm{ml}$ penicillin and $100 \mu \mathrm{g} / \mathrm{ml}$ streptomycin. When the cells reached $100 \%$ confluence, the culture were switched to adipogenic induction medium (Cyagen, Guangzhou, China) for 3 days and then switched back to maintenance medium for 1 day. Adipogenic differentiation was demonstrated by the intracellular accumulation of lipid droplets stained with Oil Red O. For Oil Red O staining, the cells were washed twice with PBS and then fixed for $30 \mathrm{~min}$ with $4 \%$ paraformaldehyde at room temperature. The cells were then stained with Oil Red O (Cyagen Biosciences, Santa Clara, CA, USA) for $30 \mathrm{~min}$ and rinsed using $70 \%$ ethyl alcohol.

Flow cytometric analysis. Flow cytometry (using a BD Accuri C6 flow cytometer; BD Biosciences, San Jose, CA, USA) analysis was performed to identify the phenotype of hUC-MSCs. Briefly, the cells were incubated for $30 \mathrm{~min}$ on ice with phycoerythrin (PE)-labeled anti-CD29 (cat. no. 557332), anti-CD45 (cat. no. 560975), anti-CD90 (cat. no. 561970), anti-CD105 (cat. no. 562380), fluorescein isothiocyanate (FITC)-labeled anti-CD19 (cat. no. 560994) and anti-CD34 (cat. no. 560942) antibodies. PE- (cat. no. 556650) and 
FITC- (cat. no. 555748) (all from BD Biosciences) conjugated IgG1 were used as isotype controls at the same concentration as the specific primary antibodies. The antibodies were used at a concentration of $0.1 \mu \mathrm{g}$ per $1 \times 10^{6}$ cells. The stained cells were washed twice with phosphate-buffered saline (PBS) and the fluorescence intensity was evaluated by flow cytometry.

Harvesting and identification of hUC-MSC-EVs. After the cells reached $90 \%$ confluency, the hUC-MSCs were washed with PBS and incubated in culture medium without serum for $48 \mathrm{~h}$. EVs were isolated from the medium by differential centrifugation and stored at $-80^{\circ} \mathrm{C}$. In brief, the medium was collected and centrifuged at $2,000 \times \mathrm{g}$ for $20 \mathrm{~min}$ at $4^{\circ} \mathrm{C}$ to remove cells and debris. Cell-free supernatants were ultracentrifuged at 100,000 x g (Beckman Coulter Optima L-90K ultracentrifuge; Beckman Coulter, Brea, CA, USA) for $1 \mathrm{~h}$ at $4^{\circ} \mathrm{C}$. The pellet was resuspended in PBS and ultracentrifuged at 100,000 x $\mathrm{g}$ for $1 \mathrm{~h}$ again. The concentration of $\mathrm{EV}$ proteins was quantified using the BCA Protein Assay kit (Beyotime Biotechnology, Haimen, China). EVs were characterized for particle size distribution and quantified by NanoSightLM10 (Malvern Instruments Ltd., Worcestershire, UK). The data were processed by Nanoparticle Tracking Analysis (NTA) 2.2 analytical software (Malvern Instruments Ltd.). hUC-MSC-EVs were also characterized using transmission electron microscopy (TEM) and scanning electron microscopy (SEM). For TEM analysis, the hUC-MSC-EVs were fixed with $2 \%$ paraformaldehyde and absorbed for 20 min to a Formvar-carbon coated grid (XXBR Technology Co., Ltd., Beijing, China), washed with PBS and further fixed with $1 \%$ glutaraldehyde for $5 \mathrm{~min}$. The grids were washed and stained with $2 \%$ uranyl acetate for $5 \mathrm{~min}$. The grids were dried and observed under a Tecnai 12 transmission electron microscope (Philips, Amsterdam, The Netherlands) at $80 \mathrm{kV}$. For SEM analysis, the hUC-MSC-EVs were fixed in Karnovsky fixative (YBscience, Shanghai, China), dehydrated in alcohol, dried on glass surface, and sputter coated with gold. The samples were observed on a Model S-4800 filed emission scanning electron microscope (S4800 II FESEM; Hitachi High-Technologies Corp., Tokyo, Japan). Images were acquired via secondary electron at a working distance of $15-25 \mathrm{~mm}$ and an accelerating voltage of $20-25 \mathrm{kV}$. The expression of CD63 (cat. no. 557288) and CD81 (cat. no. 551108) (both from BD Biosciences) on the surface of EVs was analyzed by flow cytometry. Filtered EVs were resuspended in PBS and incubated with $20 \mu \mathrm{l}$ of the fluorescent antibody CD63 and CD81 for $30 \mathrm{~min}$ on ice. The labeled EVs were analyzed with a BD Accuri C6 flow cytometer.

Internalization of MSC-EVs into breast cancer cells. The MCF-7 or MDA-MB-231 cells were incubated in medium containing DiO (green) cell-labeling and hUC-MSC-EVs were labeled using the CM-DiL Red Fluorescent Cell Linker kit (Invitrogen/Thermo Fisher Scientific) according to manufacturer's instructions and subsequently washed with PBS. The labeled hUC-MSC-EVs were incubated with the MCF-7 or MDA-MB-231 cells for $6 \mathrm{~h}$ on coverslips in a 24-well plate at $37^{\circ} \mathrm{C}$ with $5 \% \mathrm{CO}_{2}$. Cellular nuclei of MCF-7 or MDA-MB-231 cells were stained using Hoechst 33342 (Beyotime) for $30 \mathrm{~min}$ at room temperature and then viewed on a Nikon fluorescence microscope (Ti-S; Nikon).
Cell proliferation assay. MCF-7 and MDA-MB-231 cell proliferation was examined by 3-(4,5-dimethylthiazol-2-yl)-2,5-diphenyltetrazolium bromide (MTT) assay. The MCF-7 and MDA-MB-231 cells were treated with medium without hUC-MSC-EVs, or with 10,20 and $40 \mu \mathrm{g} / \mathrm{ml}$ of hUC-MSC-EVs for $24 \mathrm{~h}$, respectively. The cells were then collected and seeded into 96 -well plates with a density of $2 \times 10^{3}$ cells/well for 24,48 and $72 \mathrm{~h}$. MTT $(20 \mu \mathrm{l})$ was then added to each well followed by incubation in $37^{\circ} \mathrm{C}$ for an additional $4 \mathrm{~h}$. When the reaction was terminated, the reagent was discarded and $150 \mu \mathrm{l}$ dimethyl sulfoxide (DMSO) was added to each well for $10 \mathrm{~min}$ to ensure complete solubilization of the purple formazan crystals. The optical density was determined at $490 \mathrm{~nm}$ using an FLX 800 Fluorescence Microplate Reader (Biotek Instruments, Winooski, VT, USA).

Colony formation assay. The MCF-7 and MDA-MB-231 cells were treated with medium without hUC-MSC-EVs, or with 10 , 20 and $40 \mu \mathrm{g} / \mathrm{ml}$ of hUC-MSC-EVs for $24 \mathrm{~h}$, respectively. In certain experiments, the MCF-7 and MDA-MB-231 cells were treated with $10 \mu \mathrm{M}$ U0126, a specific extracellular-regulated kinase (ERK) inhibitor (Beyotime, Shanghai, China), for $30 \mathrm{~min}$ prior to the addition of 10,20 or $40 \mu \mathrm{g} / \mathrm{ml}$ of hUC-MSC-EVs. The cells were then collected and plated at a density of 500 cells per well in a 6-well plate. After being cultured for 10 days at $37^{\circ} \mathrm{C}$ with $5 \% \mathrm{CO}_{2}$, the cells were fixed with $4 \%$ formaldehyde for $30 \mathrm{~min}$ and stained using crystal violet (Beyotime) for $30 \mathrm{~min}$ at room temperature followed by manual (naked eye) counting of the number of cell colonies.

Transwell migration as say. Following treatment with medium containing the hUC-MSC-EVs $(10,20$ and $40 \mu \mathrm{g} / \mathrm{ml})$ for $24 \mathrm{~h}$, the MCF-7 and MDA-MB-231 cells were resuspended in $200 \mu \mathrm{l}$ serum-free medium and seeded into the upper chamber ( $8 \mu \mathrm{m}$ pore size; Corning, New York, NY, USA). The lower chamber was filled with $600 \mu \mathrm{l}$ complete medium. In certain experiments, the MCF-7 and MDA-MB-231 cells were treated with $10 \mu \mathrm{M}$ U0126 for $30 \mathrm{~min}$ prior to the addition of 10, 20 and $40 \mu \mathrm{g} / \mathrm{ml}$ of hUC-MSC-EVs. Following incubation at $37^{\circ} \mathrm{C}$ for $8 \mathrm{~h}$, the upper cells remaining in the upper membrane were wiped off smoothly, while the lower cells were fixed with $4 \%$ paraformaldehyde for $30 \mathrm{~min}$. After staining with crystal violet for $30 \mathrm{~min}$ at room temperature, 3 random fields were observed under a microscope (Ti-S; Nikon).

Cell invasion assay. The Matrigel basement membrane (BD Biosciences) was diluted to 1:3 with pre-cooled PBS. Subsequently, $30 \mu \mathrm{l}$ diluted Matrigel was added to each top chamber ( $8 \mu \mathrm{m}$ pore size; Corning) followed by incubation in $37^{\circ} \mathrm{C}$ for $30 \mathrm{~min}$. The pre-treated cells suspended in the serum-free conditioned medium were seeded into the top chamber containing coagulated Matrigel and incubated at $37^{\circ} \mathrm{C}$ for $30 \mathrm{~h}$ to allow the cells to invade into the lower membrane through Matrigel. The cells that invaded to the bottom of the upper membrane were fixed with $4 \%$ paraformaldehyde for $30 \mathrm{~min}$ and dyed with crystal violet for $30 \mathrm{~min}$ at room temperature. The cells were then examined under s microscope (Ti-S; Nikon) and the number of invaded cells was counted. 


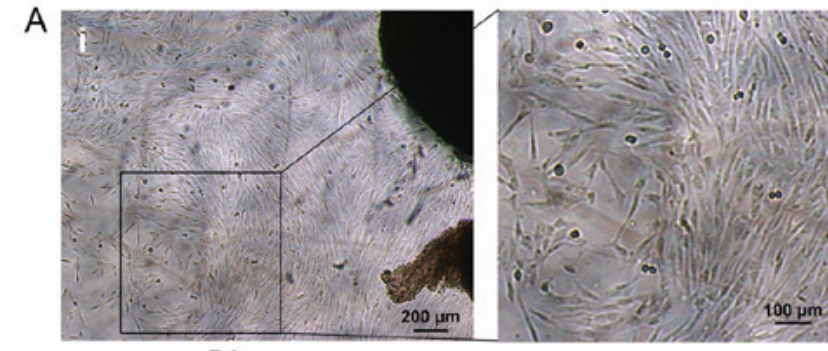

PO

B

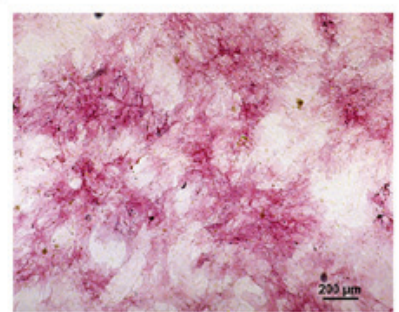

Osteoblasts

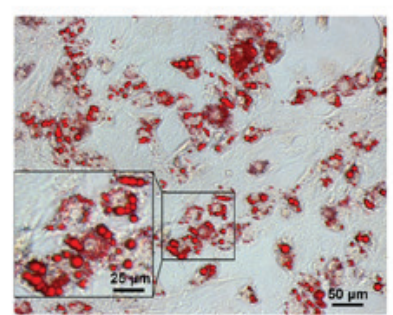

Adipocytes
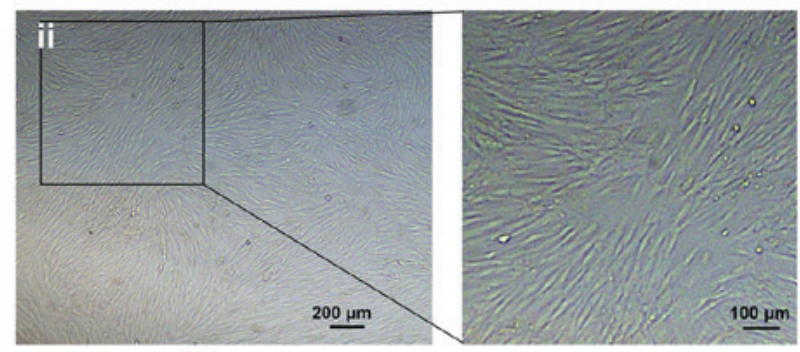

P3

C

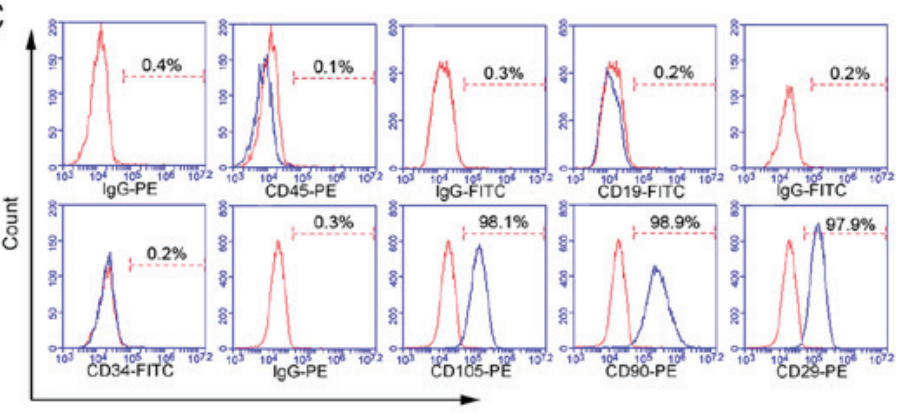

Figure 1. Characterization of hUC-MSCs. (A) The morphology of hUC-MSCs at (i) passage 0 was observed under a light microscope; the cells at (ii) passage 3 exhibited a polygonal, spindly and fibroblast-like morphology; the images on the right panels are enlarged images of the boxed areas on the left panels (left panels: magnification, x40; scale bar, $200 \mu \mathrm{m}$; right panels: magnification, x100; scale bar, $100 \mu \mathrm{m}$ ). (B) Representative images of the osteoblast (magnification, $\mathrm{x} 40$; scale bar, $200 \mu \mathrm{m}$ ) and adipocyte [magnification, x200; scale bar, $50 \mu \mathrm{m}$; the boxed area on the left (magnification, $\mathrm{x} 400$; scale bar, $25 \mu \mathrm{m}$ is an enlarged image of the boxed area on the right] differentiation of hUC-MSCs cultured in differentiation medium. The cells were analyzed using cytochemical staining with ALP staining (left panel) and Oil red O staining (right panel), respectively. (C) Flow cytometric analysis of the expression of cell surface markers related to MSCs. hUC-MSCs were positive for CD29, CD90 and CD105, but negative for CD19, CD34 and CD45. hUC-MSCs, human umbilical cord mesenchymal stem cells; ALP, alkaline phosphatase.

Scratch wound assay. The MCF-7 and MDA-MB-231 cells were treated with the medium and 10, 20 and $40 \mu \mathrm{g} / \mathrm{ml}$ of hUC-MSC-EVs for $24 \mathrm{~h}$, then harvested and seeded into 6 -well plates. When the cell confluence reached $80 \%$, the cells were scratched vertically with a sterile pipette tip, and then washed with PBS once. Wound healing was monitored and photographed at 0 and $48 \mathrm{~h}$ at multiple sites, and representative images were captured using a microscope (Ti-S; Nikon). The degree of motility $48 \mathrm{~h}$ after scratch was expressed as the percentage of wound closure and calculated as follows: (distance of scratch at $0 \mathrm{~h}$ - distance of cell migration at $48 \mathrm{~h} /$ distance of scratch at $0 \mathrm{~h}$ ) $\times 100 \%$.

Western blot analysis. Cell samples or hUC-MSC-EVs were lysed in RIPA buffer (Vazyme Biotech, Nanjing, China) containing protease inhibitors (Beyotime) and the protein concentration was then quantified. In brief, equal amounts of protein were loaded and separated on $12 \%$ SDS-polyacrylamide gels (SDS-PAGE) and then transferred onto polyvinylidene difluoride (PVDF) membranes (Beyotime). The membranes were incubated with primary antibodies at $4^{\circ} \mathrm{C}$ overnight and then washed in TBST and incubated with secondary antibody at $37^{\circ} \mathrm{C}$ for $1 \mathrm{~h}$. The target band of the proteins was then visualized using HRP substrate (Merck Millipore, Darmstadt, Germany) and analyzed using MD ImageQuant software version 5.2 (Molecular Dynamics, Inc., Sunnyvale, CA, USA). The primary antibodies used were as follows: CD63 (YT5525, 1:1,000), CD81 (YT5394, 1:1,000), p-ERK (YP1197, 1:1,000), t-ERK (YT1626, 1:1,000), N-cadherin (YT2988, 1:1,000) and E-cadherin (YT1454, 1:1,000) were purchased from ImmunoWay Biotechnology. The secondary antibodies (CW0103S, goat anti-rabbit; 1:2,000; CW0102S, goat anti-mouse, 1:2,000) were purchased from Beijing CWBio (CWBiotech, Beijing, China). GAPDH (YM3029, 1:5,000, ImmunoWay Biotechnology) was used as the loading control.

Statistical analysis. P-values were calculated by GraphPad Prism 7 (GraphPad, San Diego, CA, USA). The P-values for comparisons among groups were obtained by one-way ANOVA with Dunnetts' multiple comparisons test or an unpaired t-test with Welch correction. The results are expressed as the means \pm SD from 3 different replicates from individual assays. A P-value $<0.05$ was considered to indicate a statistically significant difference.

\section{Results}

Morphology and differentiation potential of hUC-MSCs. After around 10 days of primary culture of the tissue samples, a small population of fibroblastic cells were observed (Fig. 1A-i). A homogenous population of hUC-MSCs were obtained from the umbilical cord after 3 passages in vitro. The cells exhibited a polygonal, spindly and fibroblast-like morphology (Fig. 1A-ii). The differentiation of hUC-MSCs was apparent after 14 or 21 days of induction with specific differentiation induction medium. The hUC-MSCs were capable of differentiating into osteocytes and adipocytes, as evidenced by the positive staining of ALP (Fig. 1B, left panel) and Oil Red O (Fig. 1B, right panel), which suggests that the cells have multilineage differentiation potential. Flow cytometric analysis demonstrated that the hUC-MSCs expressed high levels of CD29 (97.9\%), CD90 (98.9\%) and CD105 (98.1\%), 
A
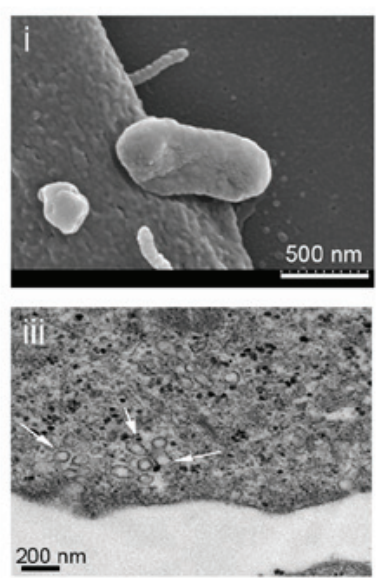
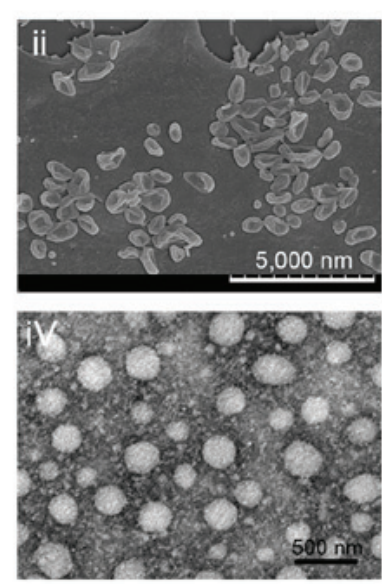
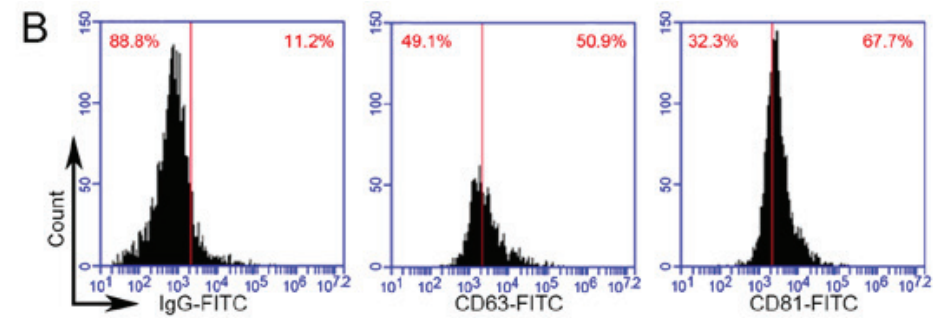

C

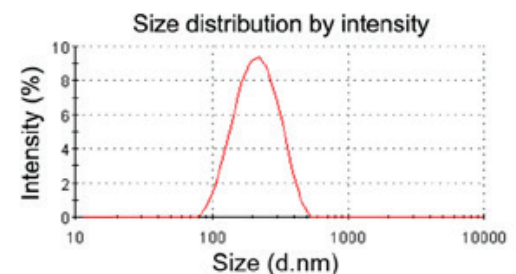

D

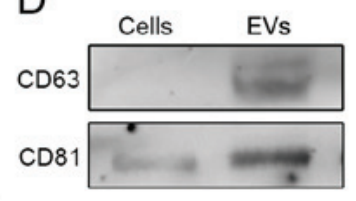

Figure 2. Identification of hUC-MSC-EVs. (A) Release of hUC-MSC-EVs from the surface of hUC-MSCs by SEM [(i) magnification, x60,000; scale bar, 500 nm; (ii) magnification, x10,000; scale bar, 5,000 nm)]. (iii) An electron microscope was used to randomly capture the different stages of hUC-MSC-EV formation and release processes; arrows indicate vesicles at the cell membrane surface (magnification, x8,900; scale bar, 200 nm). (iv) Representative micrographs of TEM obtained on collected and purified hUC-MSC-EVs (magnification, x195,000; scale bar, $500 \mathrm{~nm}$ ). (B) Flow cytometric analysis of hUC-MSC-EV protein surface expression. (C) The size distributions of hUC-MSC-EVs were identified by NTA. (D) Western blot analysis of marker CD63 and CD81 proteins in hUC-MSC-EVs. The cell lysate served as controls. hUC-MSC-EVs, human umbilical cord mesenchymal stem cell-derived extracellular vesicles; SEM, scanning electron microscopy; TEM, transmission electron microscopy; NTA, nanoparticle tracking analysis.

but were negative for CD19 (0.2\%), CD34 (0.2\%) and CD45 $(0.1 \%)$ (Fig. 1C). These results indicated that we had efficiently generated hUC-MSCs which were used in the following experiments.

Characterization of hUC-MSC-EVs. hUC-MSC-EVs were isolated and purified from the hUC-MSCs conditioned medium. The size of the isolated hUC-MSC-EVs was confirmed using TEM, SEM and NTA. The classic cup-shaped membrane particles ranged from 90-450 nm, with a mean value of $232 \mathrm{~nm}$, which suggested that the vesicles in the supernatants might be a mixture of microvesicles and exosomes (Fig. 2A and C). SEM revealed hUC-MSC-EVs with a round or oval morphology with a hypodense center and in heterogeneous sizes. TEM randomly captured the stages of hUC-MSC-EV formation and release processes (Fig. 2A-iii). Finally, the positive expression of hUC-MSC-EVs markers CD63 (50.9\%) and CD81 (67.7\%) was determined by flow cytometric analysis (Fig. 2B), and further supported by the results of western blot analysis (Fig. 2D). A BCA Protein assay for collected hUC-MSC-EVs revealed that the concentration of EV proteins was $4 \mathrm{mg} / \mathrm{ml}$. In summary, we successfully isolated hUC-MSC-EVs with intact membranes, high purity and a high concentration from hUC-MSCs.

hUC-MSC-EVs promotes breast cancer cell viability and proliferation. Firstly, we determined whether hUC-MSC-EVs can be internalized into MCF-7 and MDA-MB-231 cells. DiO (green)-labeled MCF-7 and MDA-MB-231 cells were incubated with CM-DiL (red)-labeled hUC-MSC-EVs for $6 \mathrm{~h}$ and hUC-MSC-EVs uptake by the MCF-7 or MDA-MB-231 cells was observed. The cell nuclei were stained with Hoechst 33342 and observed under a fluorescence microscope. For excluding dye contamination in DiO-labeled cells, CM-DiL was treated in the same manner as PBS and considered as a negative control. No red fluorescence was observed when the breast cancer cells were treated with the negative control medium (Fig. 3A). These results indicated that hUC-MSC-EVs could be internalized by breast cancer cells within $6 \mathrm{~h}$. To examine the effects of hUC-MSC-EVs on MCF-7 and MDA-MB-231 cells growth, we evaluated the viability of the cells treated with hUC-MSC-EVs at various concentrations $(10,20$ and $40 \mu \mathrm{g} / \mathrm{ml})$. As shown by the results of MTT assay shown in Fig. 3B and C, the hUC-MSC-EVs promoted the growth of the MCF-7 and MDA-MB-231 cells in a time- and dose-dependent manner. This finding was further confirmed by the results of colony formation assay (Fig. 3D and E). Taken together, these data suggested that the hUC-MSC-EVs promoted the proliferation of the MCF-7 and MDA-MB-231 cells.

hUC-MSC-EVs enhance the migration and invasion of breast cancer cells. To examine whether the migratory and invasive ability of the MCF-7 and MDA-MB-231 cells are affected by the hUC-MSC-EVs, these cells were incubated with 10,20 or $40 \mu \mathrm{g} / \mathrm{ml}$ hUC-MSC-EVs. The numbers of migrated and invaded breast cancer cells were significantly increased following treatment with medium containing the hUC-MSC-EVs (Fig. 4A and B). The results of the scratch wound assay also revealed that the migratory ability of the MCF-7 and MDA-MB-231 cells improved significantly following incubation with medium containing the hUC-MSC-EVs (Fig. 4C and D). Taken together, these results suggested that hUC-MSC-EVs promoted the migration and invasion of breast cancer cells.

Involvement of ERK pathway in the increased proliferation, migration and invasion of breast cancer cells induced by $h U C-M S C$-EVs. The results of western blot analysis revealed that the hUC-MSC-EVs led to the activation of the ERK pathway in the MCF-7 and MDA-MB-231 breast cancer cells (Fig. 4E and F). To determine whether the ERK pathway 
A MCF-7
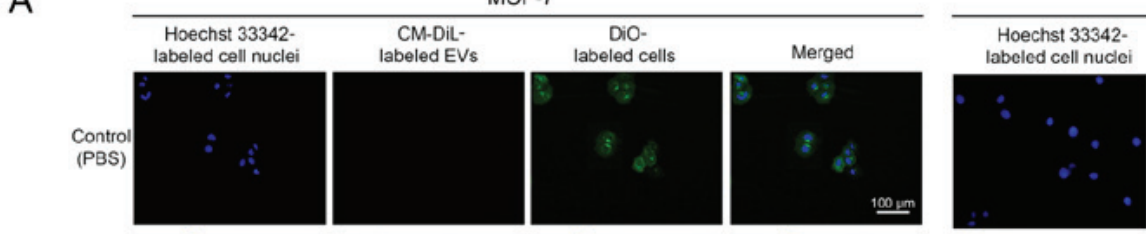
MDA-MB-231
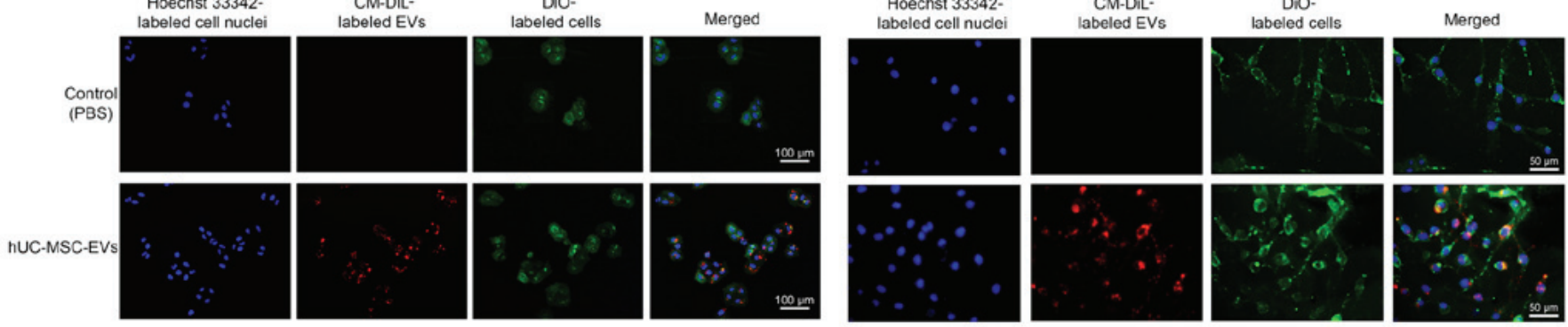

B
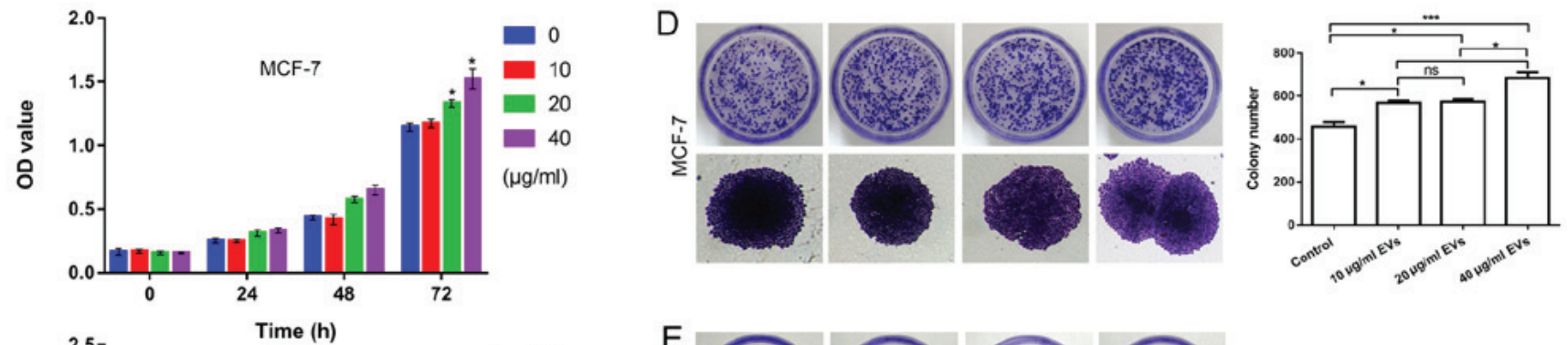

C
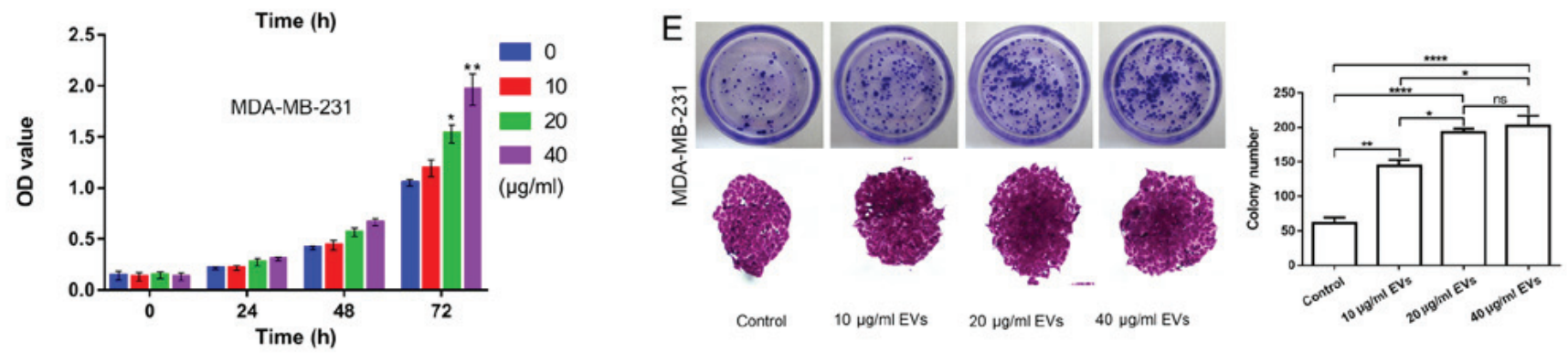

Figure 3. hUC-MSC-EVs promote breast cancer cell viability and proliferation. (A) hUC-MSC-EVs are internalized by the MCF-7 and MDA-MB-231 breast cancer cells. DiO-labeled MCF-7 and MDA-MB-231 cells incubated with CM-DiL-labeled hUC-MSC-EVs for 6 h. hUC-MSC-EVs are internalized by MCF-7 (magnification, $\mathrm{x} 200$; scale bar, $100 \mu \mathrm{m}$ ) and MDA-MB-231 cells (magnification, $\mathrm{x} 400$; scale bar, $50 \mu \mathrm{m}$ ). (B and C) MCF-7 and MDA-MB-231 cells were incubated with various concentrations of hUC-MSC-EVs for 24 to $72 \mathrm{~h}$ and cell viability was determined by MTT assay, respectively. (D and E) One representative experiment of clone formation images of MCF-7 and MDA-MB-231 cells with or without hUC-MSC-EV treatment. ${ }^{*} \mathrm{P}<0.05,{ }^{* *} \mathrm{P}<0.01,{ }^{* * *} \mathrm{P}<0.001,{ }^{* * * *} \mathrm{P}<0.0001$. ns, not significant; hUC-MSC-EVs, human umbilical cord mesenchymal stem cell-derived extracellular vesicles.

affects the proliferation and migration of the MCF-7 and MDA-MB-231 cells, we examined the colony formation, proliferation and migration of the breast cancer cells pre-treated with the ERK inhibitor, U0126, in culture with hUC-MSC-EVs by colony formation, and Transwell migration and invasion assays. As shown in Fig. 5A-F, in contrast to the above-mentioned observations that the hUC-MSC-EVs promoted the proliferation, migration and invasion of the MCF-7 and MDA-MB-231 cells, U0126 treatment of the breast cancer cells prior to the addition of hUC-MSC-EVs in culture significantly reversed the promoting effects of the hUC-MSC-EVs on the proliferation, migration and invasion of the breast cancer cells. These results suggested that the ERK pathway is involved in promotion of the proliferation, migration and invasion of the breast cancer cells upon treatment with hUC-MSC-EVs. To ascertain the effects of hUC-MSC-EVs on epithelial-mesenchymal transition (EMT), relevant markers were measured. The results of western blot analysis revealed that the breast cancer cells treated with hUC-MSC-EVs activated ERK, and increased the expression of $\mathrm{N}$-cadherin and decreased the expression of E-cadherin (Fig. 4E and F). Our data further revealed that treatment with U0126 inhibited the activation of ERK and reversed the promoting effects of the hUC-MSC-EVs on N-cadherin expression, and the suppressive effects of the hUC-MSC-EVs on E-cadherin expression in the MCF-7 and MDA-MB-231 cells (Fig. 5G and H). Taken together, these data indicated that hUC-MSC-EVs induced EMT via the activation of the ERK pathway.

\section{Discussion}

The tumor microenvironment is a dynamic system that consists of complex non-malignant cells, extracellular matrix (ECM) and signaling molecules that communicate with cancer cells. The non-malignant cells, including fibroblasts, endothelial cells and immune cells that, together with the surrounding ECM, affect tumor activity. MSCs are one of the pivotal components of the tumor microenvironment $(32,33)$. A growing body of evidence indicates that the modulatory effects of MSCs on the tumor microenvironment are mainly conferred through their paracrine activities and the secretion of various trophic factors (34). MSCs produce a panel of cytokine receptors and chemokines that interact with tumor-released molecules, enabling the migration and incorporation of MSCs into the tumor microenvironment (35). The interactions between the stromal microenvironment and tumor cells play a central role in the development and progression of cancer. When 

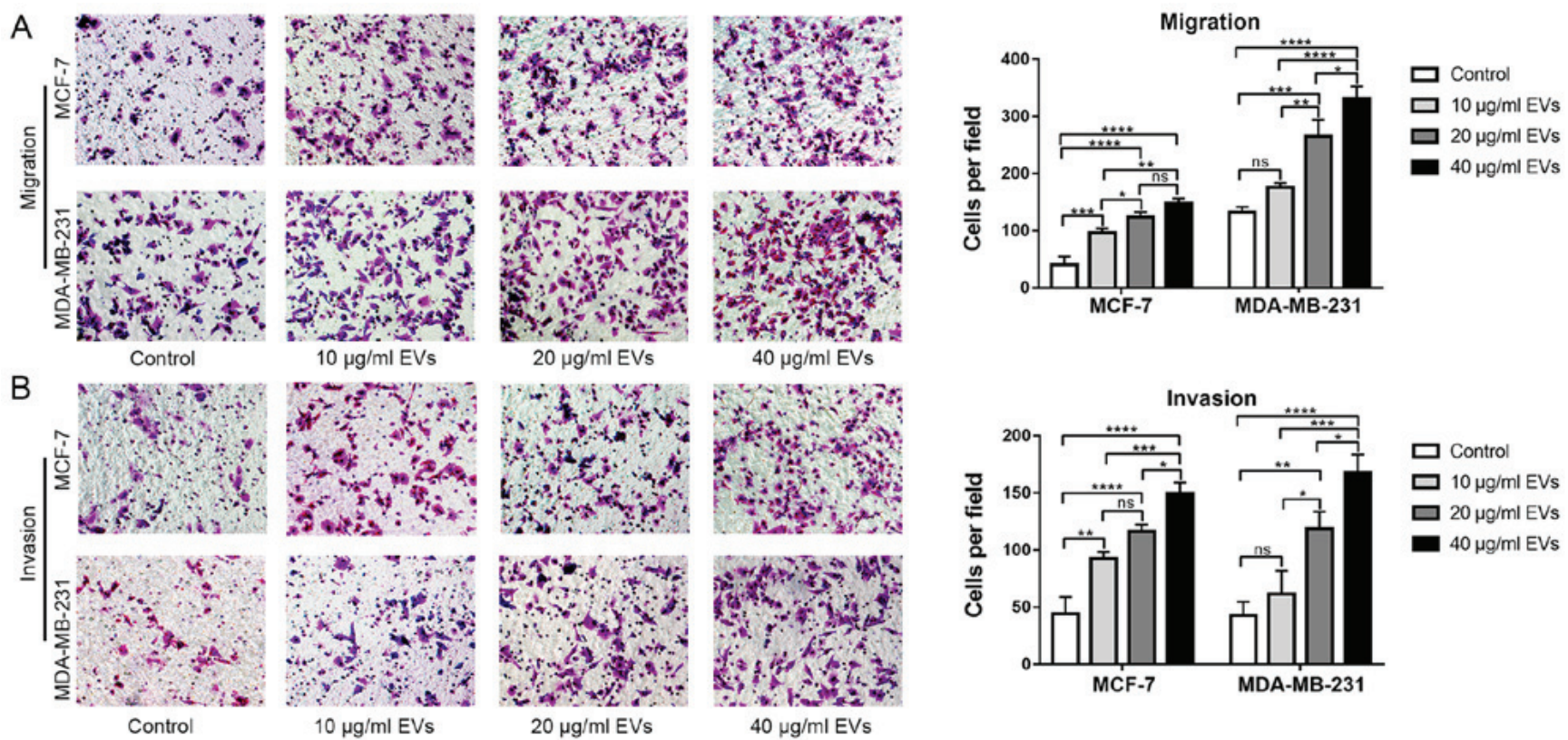

$20 \mu \mathrm{g} / \mathrm{ml}$ EVs
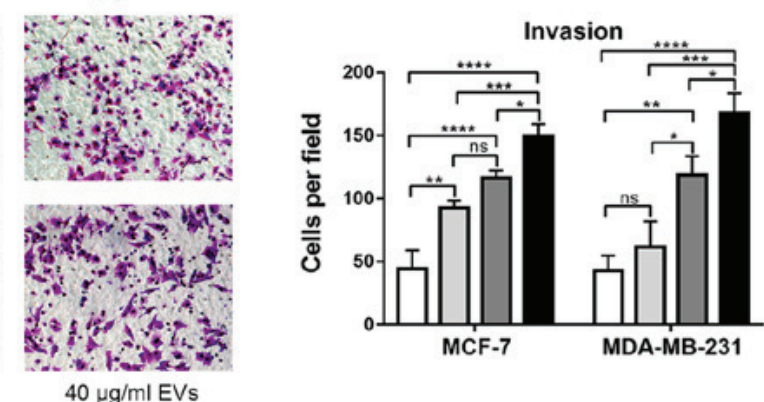

$\square$ Control

$\square 10 \mu \mathrm{g} / \mathrm{ml}$ EVs

$\square 20 \mu \mathrm{g} / \mathrm{ml}$ EVs

$40 \mu \mathrm{g} / \mathrm{ml}$ EVs

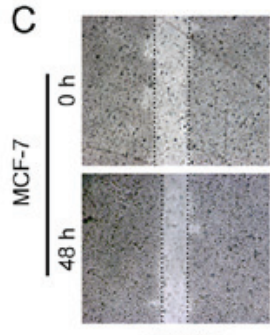

Control

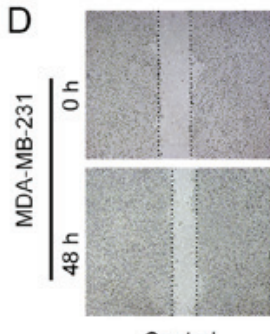

Control

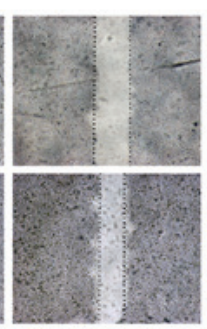

$10 \mu \mathrm{g} / \mathrm{ml}$ EVs

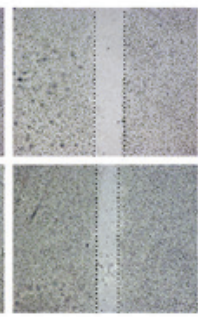

$10 \mu \mathrm{g} / \mathrm{ml} \mathrm{EVs}$

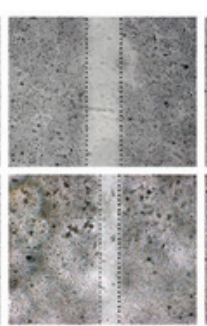

$20 \mu \mathrm{g} / \mathrm{ml}$ EVs

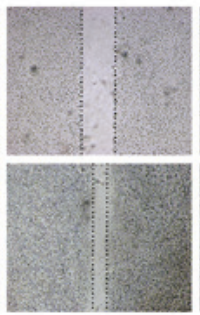

$20 \mu \mathrm{g} / \mathrm{ml} \mathrm{EVs}$

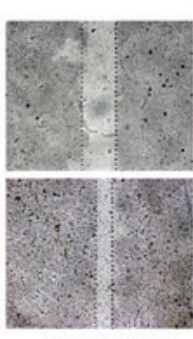

$40 \mu \mathrm{g} / \mathrm{ml} \mathrm{EVs}$

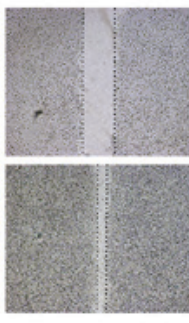

$40 \mu \mathrm{g} / \mathrm{ml}$ EVs

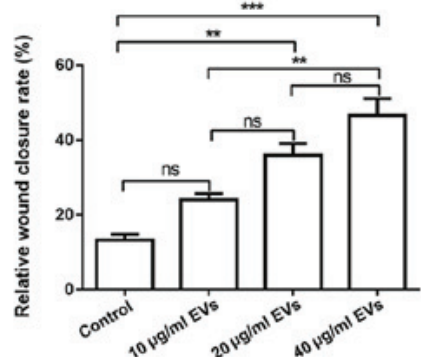

E
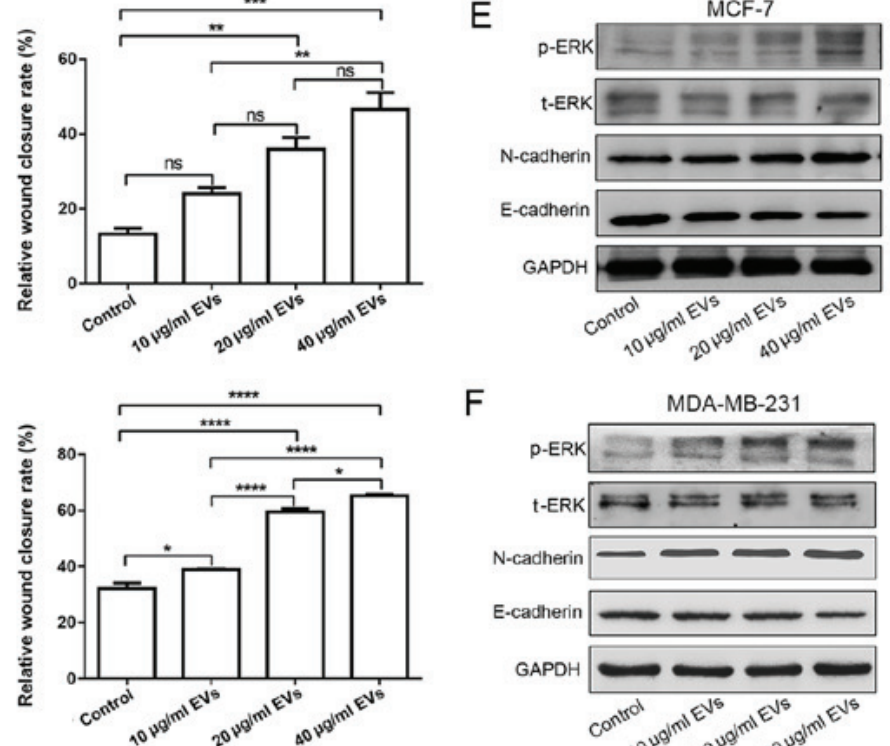

F

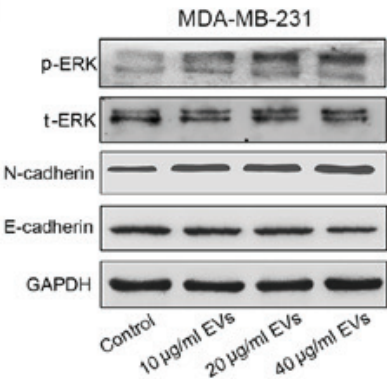

Figure 4. hUC-MSC-EVs enhanced the migration and invasion of breast cancer cells. (A and B) Transwell migration and Invasion assay for the migration ability of MCF-7 and MDA-MB-231 cells with or without hUC-MSC-EVs treatment. (C and D) Wound healing assay for the migratory ability of (C) MCF-7 and (D) MDA-MB-231 cells with or without hUC-MSC-EV treatment. Breast cancer cells treated with various concentrations of hUC-MSC-EVs (10, 20 and $40 \mu \mathrm{g} / \mathrm{ml}$ ) were subjected to wound healing assay for $48 \mathrm{~h}$. (E and F) Western blot analysis of p-ERK, t-ERK, N-cadherin and E-cadherin levels in breast cancer cells with or without hUC-MSC-EV treatment. ${ }^{*} \mathrm{P}<0.05,{ }^{* *} \mathrm{P}<0.01,{ }^{* * *} \mathrm{P}<0.001,{ }^{* * * *} \mathrm{P}<0.0001$. ns, not significant; hUC-MSC-EVs, human umbilical cord mesenchymal stem cell-derived extracellular vesicles.

in contact with tumor cells, MSCs function as regulators of proliferation, apoptosis, immune regulation and angiogenesis by producing a variety of cytokines that promote tumor progression and acquisition of chemical resistance (36).

Bone marrow-derived MSCs (BM-MSCs) are the most investigated cell source; however, the application of BM-MSCs is limited due to the invasive nature of sample collection, and reduced proliferation and multilineage differentiation potential $(37,38)$. Compared to other adult tissue-derived MSCs, hUC-MSCs are viewed as a better choice of MSCs for application due to easier isolation and expansion and low immunogenicity (39). Moreover, umbilical cord collection is convenient and is not associated with any ethical or legal issue (40).
MSCs homing to the tumor stroma has aroused interest in deciphering the function of MSCs in tumor formation and development. Despite major insight into MSC functions being obtained in recent years, the association between hUC-MSCs and tumor cells remains unclear. The tumor-promoting or suppressing effects of MSCs have been a subject of controversy over the past decade. Some studies have indicated that MSCs have oncogenic potential, while others have demonstrated that MSCs can also have the potential for antitumor application. For instance, several studies have reported that MSCs can promote tumor cell growth and metastasis in breast cancer (41), ovarian cancer (42) and lung cancer (43). Wu et al demonstrated that MSC-derived conditioned media (MSC-CM) promoted the invasion and proliferation of colorectal cancer 

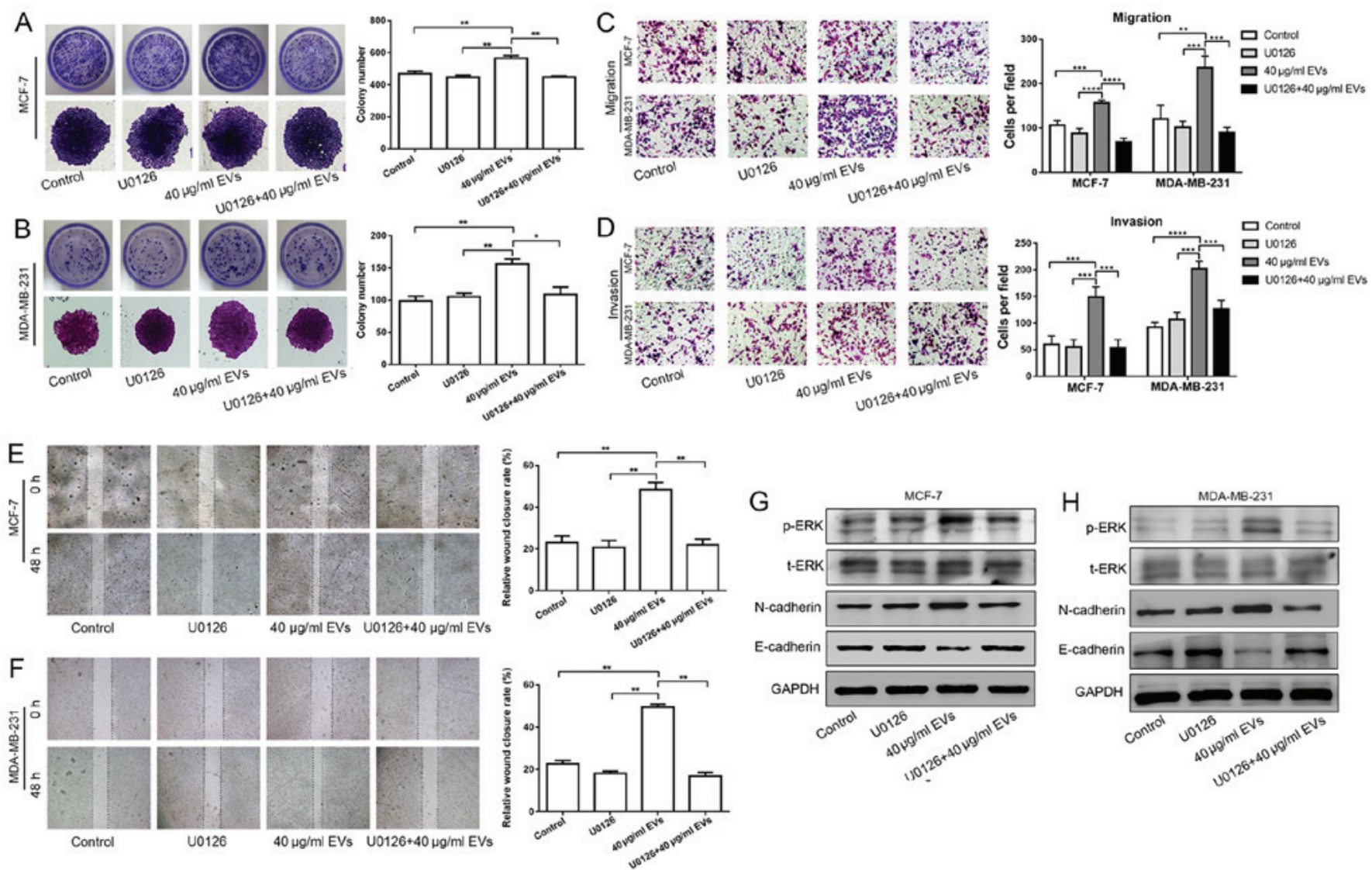

Figure 5. EMT induced by hUC-MSC-EVs is associated with increased activity of ERK pathway. (A and B) Breast cancer cells were treated with $10 \mu \mathrm{M}$ U0126 (U0126, a specific inhibitor of the ERK pathway) for $30 \mathrm{~min}$ prior to the addition of $40 \mu \mathrm{g} / \mathrm{ml} \mathrm{hUC-MSC-EVs}$. One representative experiment of clone formation images of (A) MCF-7 cells and (B) MDA-MB-231 cells is shown. (C and D) MCF-7 and MDA-MB-231 cells were treated with $10 \mu$ M U0126 for $30 \mathrm{~min}$ prior to the addition of $40 \mu \mathrm{g} / \mathrm{ml}$ hUC-MSC-EVs. (C) Transwell migration assay and (D) invasion assay for the migratory and invasive ability of the MCF-7 and MDA-MB-231 cells. (E and F) Breast cancer cells were treated with $10 \mu \mathrm{M}$ U0126 for 30 min prior to the addition of $40 \mu \mathrm{g} / \mathrm{ml} \mathrm{hUC}-\mathrm{MSC}-\mathrm{EV}$ s. Wound healing assay for the migratory ability of (E) MCF-7 cells and (F) MDA-MB-231 cells. (G) MCF-7 cells and (H) MDA-MB-231 cells were treated with $10 \mu \mathrm{M}$ U0126 for $30 \mathrm{~min}$ prior to the addition of $40 \mu \mathrm{g} / \mathrm{ml} \mathrm{hUC-MSC-EVs.} \mathrm{Subsequently,} \mathrm{p-ERK,} \mathrm{t-ERK,} \mathrm{N-cadherin} \mathrm{and} \mathrm{E-cadherin} \mathrm{levels} \mathrm{were} \mathrm{determined}$ by western blot analysis. ${ }^{*} \mathrm{P}<0.05,{ }^{* *} \mathrm{P}<0.01,{ }^{* * *} \mathrm{P}<0.001,{ }^{* * * *} \mathrm{P}<0.0001$. ns, not significant; hUC-MSC-EVs, human umbilical cord mesenchymal stem cell-derived extracellular vesicles.

cells (44). Likewise, Kim et al demonstrated that human amniotic membrane stromal cell-derived conditioned media promoted the proliferation and migration of breast cancer (45). Consistent with these previous findings, we previously found that hUC-MSCs promoted the proliferation and migration in MCF-7 and MDA-MB-231 breast cancer cells through the activation of the ERK pathway (21). These studies strongly suggested the involvement of MSCs in tumor development. On the contrary, other groups have demonstrated that MSCs inhibit tumor progression in glioblastoma, leukemia/lymphoma and liver cancer (46-48). The controversy among these results may be caused by the use of different tumor models, different sources of MSCs, the functional heterogeneity of MSCs, different experimental designs and the dose or timing of MSC injection (49,50). In summary, the safety of using MSCs in the field of cancer is worthy of attention due to their opposite effects.

The emerging evidence that cells may communicate with surrounding tumor cells and stromal cells within tumor microenvironment via the secretion of EVs has recently highlighted the importance of these studies (51). EVs can be secreted by many eukaryotic cell types, including MSCs and contain proteins, mRNAs, miRNAs, long non-coding RNAs, lipids and DNA, etc. EVs from different cell types contain distinct cargo materials and have corresponding biological and functional roles in cancer with the potential use as biomarkers and therapeutic agents. Recent findings have confirmed that EVs shuttle bioactive molecules and lead to the exchange of genetic information and metabolic reprogramming of the recipient cells, suggesting that EVs are essential for intercellular communication in the tumor microenvironment (52). Therefore, it is considered that EVs may contribute to promotion of proliferation, metastasis and invasiveness of recipient cells. Multiple reports have indicated that the secretion of EVs by MSCs is considered a novel mechanism for the paracrine effects of MSCs in tumor progression (53-56). MSC-EVs can transfer the activities of the MSCs from which they originate. In addition, MSC-EVs do not elicit acute immune rejection and tumorigenic potential. Thus, MSC-EVs represent a novel cell-free therapeutic strategy that can overcome the limitations and risks related to cell-based therapies.

In this study, we investigated the effects of hUC-MSC-EVs on breast cancer cell proliferation and migration, and the results revealed that treatment with medium containing hUC-MSC-EVs significantly enhanced cell proliferation and migration. To explore the underlying mechanisms, we examined the influence of the ERK pathway on the enhanced proliferation 
and migration of breast cancer cells induced by hUC-MSC-EVs. ERK is a member of the MAPK family which plays a key role in many cellular events, such as cell proliferation and survival (57). ERK can facilitate the differentiation of epithelial-like cells into interstitial cells, which can induce EMT to promote cell migration and metastasis $(58,59)$. EMT is a process in which epithelial cells are converted into mesenchymal cells by the loss of cell polarity. This process decreases cell-to-cell adhesion and acquires mobility, invasive capacity, stem cell-like properties, and resistance to apoptosis (60). A number of signaling pathways may be involved in cell growth and EMT. In this study, we demonstrated that the hUC-MSC-EVs promoted the proliferation and migration of breast cancer cells. We further demonstrated that the ERK inhibitor, U0126, significantly reversed the promoting effects of the hUC-MSC-EVs on the proliferation, migration and invasion of the breast cancer cells. These results suggested the involvement of the ERK pathway in the promotion of the proliferation, migration and invasion of breast cancer cells upon treatment with hUC-MSC-EVs. However, we cannot not exclude the possible involvement of other signaling pathways. In the current study, we mainly focused on the effects of hUC-MSC-EVs on the in vitro proliferation, migration and invasion of breast cancer cells. In the future, we aim to perform further in vivo studies to detect the presence of hUC-MSC or hUC-MSC-EVs and identify the key factors responsible for the EV-mediated transfer of the cancer-promoting effects.

In conclusion, in this study, we confirmed that the activation of ERK is important for the promoting effects of hUC-MSC-EVs on the proliferation of breast cancer cells. Treatment with medium containing hUC-MSC-EVs resulted in the increased activation of ERK in the MCF-7 and MDA-MB-231 breast cancer cells. Moreover, the downregulation of ERK using the inhibitor, U0126, led to an inhibition of hUC-MSC-EV-induced proliferation, thereby reversing the hUC-MSC-EV-mediated proliferation and migration of the breast cancer cells. These findings indicated that the biological alterations in breast cancer cells upon treatment with hUC-MSC-EVs may be mediated by the induction of EMT via the ERK pathway.

\section{Acknowledgements}

Not applicable.

\section{Funding}

This study was supported by the VIC Innovation Fund and the Fund for Jiangsu Specially-Appointed Professor (2014JSTPJS-53) and the College Students' Innovation Project of Jiangsu University (20181029958Y, 201810299581W).

\section{Availability of data and materials}

All data generated or analyzed during this study are included in this published article or are available from the corresponding author on reasonable request.

\section{Authors' contributions}

$\mathrm{XS}$ and $\mathrm{HC}$ contributed to the study conception and design. $\mathrm{XZ}$, TL and YC performed the experiments and acquired the data. HL and JM collected human umbilical cord, and assisted with proliferation assay and western blot. NZ, PW, YL, ML and QL analyzed and interpreted the data. HC and XS provided theoretical guidance and supervised the study. TL, XZ and HC wrote and revised the manuscript. All authors read and approved the final manuscript.

\section{Ethics approval and consent to participate}

The experiments using human samples were approved by the Research Ethics Committee of Jiangsu University. All procedures performed in this study were in accordance with the Declaration of Helsinki.

\section{Patient consent for publication}

Not applicable.

\section{Competing interests}

The authors declare that they have no competing interests.

\section{References}

1. Ruiz R, Herrero C, Strasser-Weippl K, Touya D, St. Louis J, Bukowski A and Goss PE: Epidemiology and pathophysiology of pregnancy-associated breast cancer: A review. Breast 35: 136-141, 2017.

2. Jhan JR and Andrechek ER: Effective personalized therapy for breast cancer based on predictions of cell signaling pathway activation from gene expression analysis. Oncogene 36: 3553-3561, 2017.

3. Korkaya H, Liu S and Wicha MS: Breast cancer stem cells, cytokine networks, and the tumor microenvironment. J Clin Invest 121: 3804-3809, 2011.

4. Siegel RL, Miller KD and Jemal A: Cancer Statistics, 2017. CA Cancer J Clin 67: 7-30, 2017.

5. Samavat $\mathrm{H}$ and Kurzer MS: Estrogen metabolism and breast cancer. Cancer Lett 356: 231-243, 2015.

6. Zhu A, Li Y, Song W, Xu Y, Yang F, Zhang W, Yin Y and Guan X: Antiproliferative effect of androgen receptor inhibition in mesenchymal stem-like triple-negative breast Cancer. Cell Physiol Biochem 38: 1003-1014, 2016.

7. Mao Y, Keller ET, Garfield DH, Shen K and Wang J: Stromal cells in tumor microenvironment and breast cancer. Cancer Metastasis Rev 32: 303-315, 2013.

8. Li T, Zhang J, Zhang J, Zhang N, Zeng Y, Tang S, Tao Z, Qu X, Jia J, Zhu W, et al: Nicotine-enhanced stemness and epithelial-mesenchymal transition of human umbilical cord mesenchymal stem cells promote tumor formation and growth in nude mice. Oncotarget 9: 591-606, 2017.

9. Shang F, Liu S, Ming L, Tian R, Jin F, Ding Y, Zhang Y, Zhang H, Deng $\mathrm{Z}$ and Jin Y: Human umbilical cord MSCs as new cell sources for promoting periodontal regeneration in inflammatory periodontal defect. Theranostics 7: 4370-4382, 2017.

10. Song Y, Zhao HY, Lyu ZS, Cao XN, Shi MM, Wen Q, Tang FF, Wang Y, Xu LP, Zhang XH, et al: Dysfunctional bone marrow mesenchymal stem cells in patients with poor graft function after allogeneic hematopoietic stem cell transplantation. Biol Blood Marrow Transplant 24: 1981-1989, 2018.

11. Wang M, Song L, Strange C, Dong X and Wang H: Therapeutic effects of adipose stem cells from diabetic mice for the treatment of type 2 diabetes. Mol Ther 26: 1921-1930, 2018.

12. Uccelli A, Moretta L and Pistoia V: Mesenchymal stem cells in health and disease. Nat Rev Immunol 8: 726-736, 2008.

13. Mirzaei H, Sahebkar A, Avan A, Jaafari MR, Salehi R, Salehi H, Baharvand H, Rezaei A, Hadjati J, Pawelek JM, et al: Application of mesenchymal dtem cells in melanoma: A potential therapeutic strategy for delivery of targeted agents. Curr Med Chem 23: 455-463, 2016.

14. Wang Y, Chen X, Cao W and Shi Y: Plasticity of mesenchymal stem cells in immunomodulation: Pathological and therapeutic implications. Nat Immunol 15: 1009-1016, 2014. 
15. Houthuijzen JM, Daenen LG, Roodhart JM and Voest EE: The role of mesenchymal stem cells in anti-cancer drug resistance and tumour progression. Br J Cancer 106: 1901-1906, 2012.

16. Guan J and Chen J: Mesenchymal stem cells in the tumor microenvironment. Biomed Rep 1: 517-521, 2013.

17. Kidd S, Spaeth E, Watson K, Burks J, Lu H, Klopp A, Andreeff $\mathrm{M}$ and Marini FC: Origins of the tumor microenvironment: Quantitative assessment of adipose-derived and bone marrow-derived stroma. PLoS One 7: e30563, 2012

18. Deng J, Zou ZM, Zhou TL, Su YP, Ai GP, Wang JP, Xu H and Dong SW: Bone marrow mesenchymal stem cells can be mobilized into peripheral blood by G-CSF in vivo and integrate into traumatically injured cerebral tissue. Neurol Sci 32: 641-651, 2011

19. Kidd S, Spaeth E, Dembinski JL, Dietrich M, Watson K, Klopp A, Battula VL, Weil M, Andreeff M and Marini FC: Direct evidence of mesenchymal stem cell tropism for tumor and wounding microenvironments using in vivo bioluminescent imaging. Stem Cells 27: 2614-2623, 2009.

20. Roorda BD, ter Elst A, Kamps WA and de Bont ES: Bone marrow-derived cells and tumor growth: Contribution of bone marrow-derived cells to tumor micro-environments with special focus on mesenchymal stem cells. Crit Rev Oncol Hematol 69: $187-198,2009$.

21. Li T, Zhang C, Ding Y, Zhai W, Liu K, Bu F, Tu T, Sun L, Zhu W, Zhou F, et al: Umbilical cord-derived mesenchymal stem cells promote proliferation and migration in MCF-7 and MDA-MB-231 breast cancer cells through activation of the ERK pathway. Oncol Rep 34: 1469-1477, 2015.

22. Nawaz M, Fatima F, Vallabhaneni KC, Penfornis P, Valadi H, Ekström K, Kholia S, Whitt JD, Fernandes JD, Pochampally R, et al: Extracellular vesicles: Evolving factors in stem cell biology. Stem Cells Int 2016: 1073140, 2016.

23. Rani S, Ryan AE, Griffin MD and Ritter T: Mesenchymal stem cell-derived extracellular vesicles: Toward cell-free therapeutic applications. Mol Ther 23: 812-823, 2015.

24. Zhang Y, Chopp M, Meng Y, Katakowski M, Xin H, Mahmood A and Xiong Y: Effect of exosomes derived from multipluripotent mesenchymal stromal cells on functional recovery and neurovascular plasticity in rats after traumatic brain injury. J Neurosurg 122: 856-867, 2015.

25. Gangadaran P, Hong CM and Ahn BC: Current perspectives on in vivo noninvasive tracking of extracellular vesicles with molecular imaging. BioMed Res Int 2017: 9158319, 2017.

26. EL Andaloussi S, Mäger I, Breakefield XO and Wood MJ: Extracellular vesicles: Biology and emerging therapeutic opportunities. Nat Rev Drug Discov 12: 347-357, 2013.

27. Fong MY, Zhou W, Liu L, Alontaga AY, Chandra M, Ashby J, Chow A, O'Connor ST, LiS, Chin AR, et al: Breast-cancer-secreted miR-122 reprograms glucose metabolism in premetastatic niche to promote metastasis. Nat Cell Biol 17: 183-194, 2015.

28. Goldie BJ, Dun MD, Lin M, Smith ND, Verrills NM, Dayas CV and Cairns MJ: Activity-associated miRNA are packaged in Maplb-enriched exosomes released from depolarized neurons. Nucleic Acids Res 42: 9195-9208, 2014

29. Crescitelli R, Lässer C, Szabó TG, Kittel A, Eldh M, Dianzani I, Buzás EI and Lötvall J: Distinct RNA profiles in subpopulations of extracellular vesicles: Apoptotic bodies, microvesicles and exosomes. J Extracell Vesicles 2: 2, 2013.

30. Peng J, Wang W, Hua S and Liu L: Roles of extracellular vesicles in metastatic breast cancer. Breast Cancer (Auckl): Apr 25, 2018 (Epub ahead of print). doi: 10.1177/1178223418767666.

31. Gu Y, Li T, Ding Y, Sun L, Tu T, Zhu W, Hu J and Sun X: Changes in mesenchymal stem cells following long-term culture in vitro. Mol Med Rep 13: 5207-5215, 2016

32. Gould CM and Courtneidge SA: Regulation of invadopodia by the tumor microenvironment. Cell Adhes Migr 8: 226-235, 2014.

33. Sun Z, Wang S and Zhao RC: The roles of mesenchymal stem cells in tumor inflammatory microenvironment. J Hematol Oncol 7: 14, 2014

34. Lai RC, Yeo RW and Lim SK: Mesenchymal stem cell exosomes. Semin Cell Dev Biol 40: 82-88, 2015.

35. Ramdasi S, Sarang S and Viswanathan C: Potential of mesenchymal stem cell based application in cancer. Int J Hematol Oncol Stem Cell Res 9: 95-103, 2015.

36. Ji R, Zhang B, Zhang X, Xue J, Yuan X, Yan Y, Wang M, Zhu W, Qian $\mathrm{H}$ and $\mathrm{Xu} \mathrm{W}$ : Exosomes derived from human mesenchymal stem cells confer drug resistance in gastric cancer. Cell Cycle 14: $2473-2483,2015$

37. Stenderup K, Justesen J, Clausen C and Kassem M: Aging is associated with decreased maximal life span and accelerated senescence of bone marrow stromal cells. Bone 33: 919-926, 2003.
38. Rao MS and Mattson MP: Stem cells and aging: Expanding the possibilities. Mech Ageing Dev 122: 713-734, 2001.

39. Troyer DL and Weiss ML: Wharton's jelly-derived cells are a primitive stromal cell population. Stem Cells 26: 591-599, 2008.

40. Secco M, Zucconi E, Vieira NM, Fogaça LL, Cerqueira A, Carvalho MD, Jazedje T, Okamoto OK, Muotri AR and Zatz M: Multipotent stem cells from umbilical cord: Cord is richer than blood! Stem Cells 26: 146-150, 2008.

41. Yu PF, Huang Y, Han YY, Lin LY, Sun WH, Rabson AB, Wang Y and Shi YF: TNF $\alpha$-activated mesenchymal stromal cells promote breast cancer metastasis by recruiting $\mathrm{CXCR} 2^{+}$neutrophils. Oncogene 36: 482-490, 2017

42. Coffman LG, Choi YJ, McLean K, Allen BL, di Magliano MP and Buckanovich RJ: Human carcinoma-associated mesenchymal stem cells promote ovarian cancer chemotherapy resistance via a BMP4/HH signaling loop. Oncotarget 7: 6916-6932, 2016.

43. Dong L, Pu Y, Zhang L, Qi Q, Xu L, Li W, Wei C, Wang X, Zhou S, Zhu J, et al: Human umbilical cord mesenchymal stem cell-derived extracellular vesicles promote lung adenocarcinoma growth by transferring miR-410. Cell Death Dis 9: 218, 2018

44. Wu XB, Liu Y, Wang GH, Xu X, Cai Y, Wang HY, Li YQ, Meng HF, Dai F and Jin JD: Mesenchymal stem cells promote colorectal cancer progression through AMPK/mTOR-mediated NF- $\kappa$ B activation. Sci Rep 6: 21420, 2016.

45. Kim SH, Bang SH, Kang SY, Park KD, Eom JH, Oh IU, Yoo SH, Kim CW and Baek SY: Human amniotic membrane-derived stromal cells (hAMSC) interact depending on breast cancer cell type through secreted molecules. Tissue Cell 47: 10-16, 2015.

46. Marofi F, Vahedi G, Biglari A, Esmaeilzadeh A and Athari SS: Mesenchymal stromal/stem cells: A new era in the cell-based targeted gene therapy of cancer. Front Immunol 8: 1770, 2017.

47. Song N, Gao L, Qiu H, Huang C, Cheng H, Zhou H, Lv S, Chen L and Wang J: Mouse bone marrow-derived mesenchymal stem cells inhibit leukemia/lymphoma cell proliferation in vitro and in a mouse model of allogeneic bone marrow transplant. Int $\mathrm{J}$ Mol Med 36: 139-149, 2015

48. Yulyana Y, Ho IA, Sia KC, Newman JP, Toh XY, Endaya BB, Chan JK, Gnecchi M, Huynh H, Chung AY, et al: Paracrine factors of human fetal MSCs inhibit liver cancer growth through reduced activation of IGF-1R/PI3K/Akt signaling. Mol Ther 23: 746-756, 2015.

49. Klopp AH, Gupta A, Spaeth E, Andreeff M and Marini F III: Concise review: Dissecting a discrepancy in the literature: do mesenchymal stem cells support or suppress tumor growth? Stem Cells 29: 11-19, 2011

50. Melzer C, Yang Y and Hass R: Interaction of MSC with tumor cells. Cell Commun Signal 14: 20, 2016.

51. Chin AR and Wang SE:Cancer-derived extracellular vesicles: The 'soil conditioner' in breast cancer metastasis? Cancer Metastasis Rev 35: 669-676, 2016.

52. He C, Zheng S, Luo Y and Wang B: Exosome theranostics: Biology and translational medicine. Theranostics 8: 237-255, 2018.

53. Ridge SM, Sullivan FJ and Glynn SA: Mesenchymal stem cells: Key players in cancer progression. Mol Cancer 16: 31, 2017.

54. Yang H, Zhang H, Ge S, Ning T, Bai M, Li J, Li S, Sun W, Deng T, Zhang L, et al: Exosome-derived miR-130a activates angiogenesis in gastric cancer by targeting C-MYB in vascular endothelial cells. Mol Ther 26: 2466-2475, 2018.

55. Colombo M, Raposo G and Théry C: Biogenesis, secretion, and intercellular interactions of exosomes and other extracellular vesicles. Annu Rev Cell Dev Biol 30: 255-289, 2014.

56. Xu R, Greening DW, Zhu HJ, Takahashi N and Simpson RJ: Extracellular vesicle isolation and characterization: Toward clinical application. J Clin Invest 126: 1152-1162, 2016.

57. Platanias LC: Map kinase signaling pathways and hematologic malignancies. Blood 101: 4667-4679, 2003.

58. Xiao J, Yang S, Shen P, Wang Y, Sun H, Ji F and Zhou D: Phosphorylation of ETV4 at Ser73 by ERK kinase could block ETV4 ubiquitination degradation in colorectal cancer. Biochem Biophys Res Commun 486: 1062-1068, 2017.

59. Jia S, Lu J, Qu T, Feng Y, Wang X, Liu C and Ji J: MAGI1 inhibits migration and invasion via blocking MAPK/ERK signaling pathway in gastric cancer. Chin J Cancer Res 29: 25-35, 2017.

60. Talbot LJ, Bhattacharya SD and Kuo PC: Epithelial-mesenchymal transition, the tumor microenvironment, and metastatic behavior of epithelial malignancies. Int J Biochem Mol Biol 3: 117-136, 2012 . 